\title{
The evaluating of efficacy of McKenzie exercises, Massage and foot Reflexology on pain and disability of men with mechanical chronic low back pain
}

\author{
Roozbeh Sanadgol $^{1}(\mathrm{Ms})$, Ahmad Ebrahimi Atri ${ }^{2}(\mathrm{PhD})$, Seyd Ali Akbar Hashemi Javaheri ${ }^{3}(\mathrm{PhD})$ \\ ${ }^{1}$ Department of Sport Injuries and Corrective Exercises, Faculty of Sport Sciences and Physical Education, \\ Ferdowsi University of Mashhad International Campus, Mashhad, Iran \\ ${ }^{2}$ Associate Professor, Department of Sport Injuries and Corrective Exercises, Faculty of Sport Sciences and \\ Physical Education, Ferdowsi University of Mashhad (FUM), Mashhad, Iran \\ ${ }^{3}$ Associate Professor, Department of Sport Injuries and Corrective Exercises, Faculty of Sport Sciences and \\ Physical Education, Ferdowsi University of Mashhad (FUM), Mashhad, Iran
}

\begin{abstract}
Chronic low-back pain (CLBP) affects most people at some point in their lives. The aim of this study was to evaluate the efficiency of 3 methods which are popular and known as non-invasive way in rehabilitation of CLBP. 60 men in age of group 25-45 with CLBP were randomly divided into four groups (McKenzie, massage, reflexology and control) and instructed to perform McKenzie exercise for 8 week, massage and foot reflexology for 10 days. Patient were assessed by McGill pain questioner (MPQ) and Oswestry Disability Index (ODI), based on pain feeling and the ability to do routine activity of life before starting the study (Pre-test Data) and at the end of study procedure (post-test Data). Results were analyzed by Paired T test, one way ANOVA and Tukey post hock. There was no significantly difference in Pre-treatment session between the 4 groups. MPQ and ODI were significantly lower in post-treatment sessions as compared to pretreatment values in experimental groups (McKenzie, massage and foot reflexology). Significant decrease in MPQ and ODI values were found in all experimental groups, but no difference in efficacy were found between these groups. However the result that reach from comparison between each of experimental group and control group, showed that the experimental groups were significantly effective. McKenzie exercise, massage and foot reflexology in men with mechanical chronic low-back pain reduce pain and improved disability. Researchers were not found any differences between these 3 methods as compare with each other. Due to the results, Authors suggest that may be using massage therapy or foot reflexology, for patients with CLBP, is better and more effective if therapists are looking for treating in shortest possible duration.
\end{abstract}




\section{Introduction}

$\mathrm{J}$ ust like Toothache and flew, chronic low back pain (CLBP) is a popular concern cause pain and disability. 75 up to 80 percent of people experience it at least once in their lives (1, $3)$. No one is safe from disability produce by CLBP and this condition is not depend on a specific gender, nationality, age or culture. This dilemma is turned to one of the most important reasons of functional disability in all society; the CLBP treatment cost, without any significant improvement in method and results, is getting increase yearly $(2,3)$.

Due to CLBP prevalence in society and its expensive treatment cost, many deferent therapies and treatment methods have been designed and suggested. However, treatment methods are getting improve every day, these protocols are cause heavy charge and take too much time. In meantime, exercise therapy and complementary medicine (such as massage and foot reflexology) gain a valuable and critical position in treatment (6).

It seems that pain is the first pathologic symptom of low back pain (LBP) which it cause limitation during activities. Expertises have so many pain classifications. Some of them claim that the chronic pain is a pain which continue more than 6 months while there is another group is exist who are believe if the pain getting continue for 3 months or more, we can call it a chronic pain $(12,13)$. Background results are demonstrated there is a bound between pain and functional disability and fear of pain repetition in different situations cause limitation in patients' activities (1).

The reason of 97 percent of low back pains are mechanical, 1 percent is non mechanical and 2 percent of it because of abdominal disorders (2, 16).

McKenzie exercises are used by therapists over the past few decades, and many people known them as a good method to reduce pain and treating low back pain. Thus, past researches are shown various differences in results $(7,8)$. Massage and foot reflexology are new method in CLBP therapy and few researchers had been studied on this methods, and they were mentioned that this field of treatment need more investigations $(1,9,10,11)$.

Previous studies were demonstrate that active therapy can improve functional ability and reduce pain, when it specifically has both exercise and patient's collaboration (17). McKenzie exercise is an efficient protocol to treat CLBP $(7,18)$. He believes that bad postures are lead to decrease at lumbar curve; as a consequence, soft tissue will be stretched and pain might emerge. So, by make lumbar curve correct and maintain it, therapist can decrease pain (7). This group of exercises is focused on spine erector muscles strengthening and stretching of anterior trunk muscles (18). Many researches shown that McKenzie exercises has affected large muscles (19).

Due to mankind body complication and need to health maintaining, Massage therapy is getting more important because of its effects on soft tissue and reduce pains. Massage induces an increasing in blood circle in the target area and tissue relaxation which it causes pain reduction $(20,16)$.

Reflexology is an alternative medicine involving application of pressure to the foot with thumb, finger and hand techniques without the use of oil or lotion. It is based on a system of zone and reflex areas that reflect an image of the body on the feet, with the premise that such work affects a physical change to the body (34).

Owing to the fact that finding new ways of therapy is highly important and generality of McKenzie exercises and inadequate studies about massage and reflexology, scholars decide to evaluate the efficiency of these three protocols.

\section{MATERIAL AND METHODS}

The present study is a clinical trial. Based on terms and conditions of the study, subjects had to be made homogeneous. The population consisted men with chronic low back pain who had this pain at least 12 weeks. Their age ranged from 25 to 45 years and they were non-athletes. From the population, a sample of 60 cases was selected based on simple random sampling and 
were subsequently divided into four equal group (McKenzie "group A", massage "group B", reflexology "group $\mathrm{C}^{\text {" }}$ and control "group D") and instructed to perform McKenzie exercise for 8 week, massage and foot reflexology for 10 days. It should be noted that all patients participated in the trial voluntarily and with personal consent. In this trial the independent variables are include three treatment protocol and the related variables are pain and function of patients. Subjects were assessed by McGill pain questioner (MPQ) and Oswestry Disability Index (ODI), based on pain feeling and the ability to do routine activity of life before starting the study (Pre-test Data) and at the end of study procedure (post-test Data) In order to collect information.

Results were analyzed by Paired T test, one way ANOVA and Tukey post hock. Additionally, K-S test used to evaluate the normality of groups and levene's test used to assess the equality of variances for variables. All tests were performed by using SPSS version 16 .

\section{RESULTS}

The demographic and general characteristics of the study subjects are shown in table 1 . After analyzing data no significantly difference has been saw in Pre-treatment session between the 4 groups. MPQ and ODI were significantly lower in post-treatment sessions as compared to Pre-treatment values in experimental groups (McKenzie, massage and foot reflexology). Significant decrease in MPQ and ODI values were found in all experimental groups (table 2), but no difference in efficacy were found among them (table 3). However, the results that reach from comparison between each of experimental group and control group showed the experimental groups were significantly effective.

\section{DISCUSSION and CONCLUSION}

The present study aimed to evaluate the efficacy of McKenzie exercises, Massage and foot Reflexology on pain and function of men with mechanical chronic low back pain.
About McKenzie exercises, results are compatible with previous studies which all of them known this protocol as an effective method $(24,25,26,27,28)$. This group of exercises is focused on spine erector muscles strengthening and stretching of anterior trunk muscles in order to increase strength of the target muscles and decrease the lumbar curve (18).

Massage results are same as the past researches $(1,30,16,14,20)$. Muscle spasm is extremely uncomfortable, being both the product and the cause of pain. Massage reduces discomfort, relieves the associated muscle spasm and permits improve function (36). Massage has traditionally been used to relieve pain although research has only recently provided an acceptable physiological explanation of this observation. Massage produces short-lived analgesia by activating the 'pain gate' mechanism (37). Cutaneous mechanoreceptors are stimulated by touch and transmit information within large nerve fibers to the spinal cord. These impulses block the passage of painful stimuli entering the same spinal segment along small, slowly conducting neurons (36). In addition, massage has been used to relax the sick or prepare hose about to under mark some demanding physical task and most people know of the pleasurable relaxation that follows a gentle massage. Physical relaxation, whether induced for enjoyment or the treatment of pain, can improve blood flow, reduce muscle tone and tension in connective tissue, and thus accelerate physical repair. Relaxation will also increase individual tolerance to further, less comfortable, therapy or athletic trial (36).

Reflexology results are same as the previous trials $(10,31,32,33,34,35)$. Function and mechanism of reflexology is still an aura of ambiguity. However some theories have been put forward in this regard including: the gate control theory of pain, nerve impulse theory, increase of endorphins and encephalon secretion that result in improve pain control, improvement of lymphatic flow and strengthening the immune system, improvement of nerve and blood flow and excretion of toxin from the body that ultimately improve patient's treatment (32). There is no consensus among reflexologists on how reflexology is supposed to work; a unifying 
theme is the idea that areas on the foot correspond to areas of the body including spine (38). Reflexologists posit that the blockage of an energy field, invisible life force, or Qi, can prevent healing (38). Another tenet of reflexology is the belief that practitioners can relieve stress and pain in other parts of the body through the foot manipulation. One claimed explanation is that the pressure received in the feet may send signals that 'balance' the nervous system or release chemicals such as endorphins that reduce stress and pain (38).
Regarding to the positive outcomes of this study, it is concluded that all these treatment protocols are beneficial. Due to the length of each protocol, researchers suggest massage and reflexology in order to treat patients with mechanical chronic low back pain along with reducing pain and improving function.

Table 1. The demographic and general characteristics of the study subjects (McKenzie = Group A; Massage $=$ Group B; Reflexology = Group C; Control = Group D)

\begin{tabular}{l|l|l|l|l}
\hline Variable & Group A $(\mathrm{n}=15)$ & Group B $(\mathrm{n}=15)$ & Group C $(\mathrm{n}=15)$ & Group D $(\mathrm{n}=15)$ \\
\hline Age (years) & $37.53 \pm 6.32$ & $34.73 \pm 6.22$ & $36.60 \pm 5.19$ & $33.80 \pm 6.51$ \\
\hline Height (centimeter) & $175.8 \pm 3.96$ & $176.2 \pm 3.42$ & $175.9 \pm 1.70$ & $174.9 \pm 1.90$ \\
\hline Weight (kilogram) & $82.00 \pm 8.29$ & $83.33 \pm 5.19$ & $83.46 \pm 5.51$ & $79.86 \pm 7.52$ \\
\hline BMI & $26.48 \pm 2.08$ & $26.82 \pm 1.10$ & $26.97 \pm 1.88$ & $26.07 \pm 2.19$ \\
\hline
\end{tabular}

Table 1. The demographic and general characteristics of the study subjects (McKenzie = Group A;

\begin{tabular}{l|l|l|l|l|l}
\multicolumn{6}{c}{ Massage = Group B; Reflexology = Group C; Control = Group D) } \\
\hline Variable & & Group A $(\mathrm{n}=15)$ & Group B $(\mathrm{n}=15)$ & Group C (n=15) & Group D (n=15) \\
\hline \multirow{4}{*}{ Pain } & Pre & 41.066 & 41.533 & 45.266 & 40.533 \\
\cline { 2 - 6 } & Post & 24.066 & 25.733 & 29.933 & 42.400 \\
\cline { 2 - 6 } & $\mathrm{T}$ & 12.021 & 10.960 & 6.782 & -2.029 \\
\cline { 2 - 6 } & P value & 0.000 & 0.000 & 0.000 & 0.062 \\
\hline \multirow{6}{*}{ Disability } & Pre & 36.133 & 33.066 & 36.666 & 38.533 \\
\cline { 2 - 6 } & Post & 20.933 & 17.866 & 18.933 & 38.200 \\
\cline { 2 - 6 } & T & 10.472 & 8.172 & 8.175 & 0.572 \\
\cline { 2 - 6 } & P value & 0.000 & 0.000 & 0.000 & 0.576 \\
\hline
\end{tabular}


Table 3. Tukey post hock test results $($ McKenzie $=$ Group A; Massage $=$ Group B; Reflexology $=$ Group C; Control = Group D)

\begin{tabular}{|c|c|c|c|c|}
\hline Variable & I & $\mathbf{J}$ & Man differences & $P$ value \\
\hline \multirow{12}{*}{ Pain } & \multirow{3}{*}{ Group A } & Group B & -1.666 & 0.892 \\
\hline & & Group C & -5.866 & 0.069 \\
\hline & & Group D & -18.333 & 0.000 \\
\hline & \multirow{3}{*}{ Group B } & Group A & 1.666 & 0892 \\
\hline & & Group C & -4.200 & 0.286 \\
\hline & & Group D & -16.666 & 0.000 \\
\hline & \multirow{3}{*}{ Group C } & Group A & 5.686 & 0.069 \\
\hline & & Group B & 4.200 & 0.286 \\
\hline & & Group D & -12.466 & 0.000 \\
\hline & \multirow{3}{*}{ Group D } & Group A & 18.833 & 0.000 \\
\hline & & Group B & 16.666 & 0.000 \\
\hline & & Group C & 12.466 & 0.000 \\
\hline \multirow{12}{*}{ Disability } & \multirow{3}{*}{ Group A } & Group B & 3.066 & 0.490 \\
\hline & & Group C & 2.000 & 0.790 \\
\hline & & Group D & -17.266 & 0.000 \\
\hline & \multirow{3}{*}{ Group B } & Group A & -3.066 & 0.490 \\
\hline & & Group C & -1.066 & 0.960 \\
\hline & & Group D & -20.333 & 0.000 \\
\hline & \multirow{3}{*}{ Group C } & Group A & -2.000 & 0.790 \\
\hline & & Group B & 1.066 & 0.960 \\
\hline & & Group D & -19.266 & 0.000 \\
\hline & \multirow{3}{*}{ Group D } & Group A & 17.266 & 0.000 \\
\hline & & Group B & 20.333 & 0.000 \\
\hline & & Group C & 19.266 & 0.000 \\
\hline
\end{tabular}

\section{Conclusion}

McKenzie exercise, massage and foot reflexology in men with mechanical chronic low-back pain reduce pain and improved disability. Researchers were not found any differences between these 3 methods as compare with each other. Due to the results, Authors suggest that may be using massage therapy or foot reflexology, for patients with CLBP, is better and more effective if therapists are looking for treating in shortest possible duration.

\section{Acknowledgment}

Here I should give my best regards to $\mathrm{Mr}$ Abolfazl Shahrakinasab who if not there I was not be able to do this task, and also those who helping me or correcting me by their words.

\section{References}

1. Panahi F, Kamali Sarvestani F. Massage and modality effects on treatment of sub-acute and chronic non specific low back pain. Journal of Kermanshah University of Medical Sciences. 2011;15(5).

2. Palastanga NP, Soames R. Anatomy and human movement: structure and function: Churchill Livingstone; 2011.

3. Haldeman SD, Kirkaldy-Willis WH, Bernard TN. An Atlas of Back Pain: Parthenon Publishing Group; 2002.

4. Wanek V, Brenner H, Novak P, Reime B. Back pain in industry: prevalence, correlation with work conditions and requests for reassignment by employees. Gesundheitswesen (Bundesverband der Ärzte 
des Öffentlichen Gesundheitsdienstes (Germany)). 1998;60(8-9):513.

5. Hazard R. Chronic low back pain and disability: the efficacy of functional restoration. Bulletin (Hospital for Joint Diseases (New York, NY)). 1996;55(4):213.

6. Sertpoyraz F, Eyigor S, Karapolat H, Capaci $\mathrm{K}$, Kirazli Y. Comparison of isokinetic exercise versus standard exercise training in patients with chronic low back pain: a randomized controlled study. Clinical rehabilitation. 2009;23(3):238-47.

7. Nasseri N. Physiotherapy in Orthopedic disorders: Sobh-e-sa'adat; 2005. 360 p.

8. Machado LAC, De Souza MvS, Ferreira PH, Ferreira ML. The McKenzie method for low back pain: a systematic review of the literature with a meta-analysis approach. Spine. 2006;31(9):E254-E62.

9. nazemzadeh $\mathrm{m}$, jalalodini $\mathrm{a}$, rezvani amin $\mathrm{m}$, yousefian $n$, poornamdar $z$, ghaljeh $\mathrm{m}$. The effect of foot reflexology massage on pain intensity in patients with chronic low back pain visited to physical therapy unit in Baghiathallah hospital in Tehran. 2. 2012;2(3):1-8.

10. Quinn F, Hughes CM, Baxter G. Reflexology in the management of low back pain: a pilot randomised controlled trial. Complementary Therapies in Medicine. 2008;16(1):3-8.

11. Furlan AD, Imamura M, Dryden T, Irvin E. Massage for low-back pain. Cochrane Database Syst Rev. 2008;4(4).

12. Thorn BE. Cognitive therapy for chronic pain: A step-by-step guide: Guilford Press; 2004.

13. Bogduk N. Management of chronic low back pain. Medical Journal of Australia. 2004;180(2):79-83.

14. Aure OF, Nilsen JH, Vasseljen O. Manual therapy and exercise therapy in patients with chronic low back pain: a randomized, controlled trial with 1-year follow-up. Spine. 2003;28(6):525-31.

15. Andersson GB. Epidemiological features of chronic low-back pain. The lancet. 1999;354(9178):581-5.
16. Furlan A, Imamura M, Dryden $T$, Irvin E. Massage for low back pain: an updated systematic review within the framework of the Cochrane Back Review Group. Spine. 2009;34(16):1669.

17. Twomey LT, Taylor JR, Taylor JR. Physical therapy of the low back: Churchill Livingstone; 2000.

18.Skikic E, Suad T. The Effects of Mckenzie Exercsies for Patients with Low Back Pain, Our Experience. The fourth edition of the Bosnian Journal of Basic Medical Sciences we dedicate to the memory of the most meritorious man for the foundation and development of the medical science in general and all basic sciences at Faculty of Medicine of Sarajevo and in whole Bosnia and Herzegovina, as well. 2003;3:70.

19.Souza GM, Baker LL, Powers CM. Electromyographic activity of selected trunk muscles during dynamic spine stabilization exercises. Archives of physical medicine and rehabilitation. 2001;82(11):1551-7.

20. Ernst E. Massage therapy for low back pain: a systematic review. Journal of pain and symptom management. 1999;17(1):65-9.

21. Lynn J. Using complementary therapies: reflexology Professional Nurse 1997;11:321-2.

22. Nejad SK, Atri AE, Javaheri SAAH, Akbari H, Kheirabadi N. The Comparison of Three Rehabilitation Protocol on Pain and Performance in Women Patients with NonSpecific Chronic Low Back Pain. 2013.

23. Momeni S, Moghaddasi A, Farahpour N, Golpayegani M, Abbasi Darehbidi M. The effect of exercise therapy on pain, disability and endurance of trunk flexor-extensor muscles in women with chronic idiopathic low back pain. Journal of Kermanshah University of Medical Sciences. 2011;15.

24. Larri MS, Bakhtiary AH, Hedayati R, Rezasoltani A, Ghorbani R, et al. Comparison the effect of stabilization and McKenzie exercises on pain, disability and lumbar multifidus muscle size in women with chronic nonspecific low back pain. 2012.

25. Mbada CE, Ayanniyi O, Ogunlade SO, Orimolade EA, Oladiran AB, Ogundele AO. 
Influence of Mckenzie protocol and two modes of endurance exercises on healthrelated quality of life of patients with longterm mechanical low-back pain. The Pan African medical journal. 2014;17(Suppl 1).

26. Murtezani, Ardiana, et al. "A comparison of McKenzie therapy with electrophysical agents for the treatment of work related low back pain: A randomized controlled trial." Journal of back and musculoskeletal rehabilitation (2014).

27. Petersen, Tom, et al. "The McKenzie method compared with manipulation when used adjunctive to information and advice in low back pain patients presenting with centralization or peripheralization: a randomized controlled trial." Spine 36.24 (2011): 1999-2010.

28. Skikic E, Suad T. The Effects of Mckenzie Exercises for Patients with Low Back Pain, Our Experience. The fourth edition of the Bosnian Journal of Basic Medical Sciences we dedicate to the memory of the most meritorious man for the foundation and development of the medical science in general and all basic sciences at Faculty of Medicine of Sarajevo and in whole Bosnia and Herzegovina, as well. 2003;3:70.

29. McKenzie R. Treat Your Own Back. Seventh ed: Spinal Publications; 1997.

30. Khanzadeh R, Hashemi Javaheri AA, Omidi Kashani F, Zandi M, Khodabakhshi M. The effect of combined therapeutic protocol (Therapeutic exercises and Massage) on the pain and physical performance in men with chronic low back pain due to lumbar disk herniation. EVIDENCE BASED CARE. 2012.

31. Bennedbæk O, Viktor J, Carlsen K, Roed H, Vinding $\mathrm{H}$, Lundbye-Christensen S. (Infants with colic. A heterogenous group possible to cure? Treatment by pediatric consultation followed by a study of the effect of zone therapy on incurable colic). Ugeskrift for laeger. 2001;163(27):3773-8.

32. Movaghar M, Fathi M, Zandi M. The Effect of Foot Reflexology on the Reduction of Low Back Pain Caused by Discopathy. ZUMS Journal. 2012; 20 (83):62-69.
33. Nazemzadeh $M$, jalalodini $A$, rezvani amin $\mathrm{M}$, yousefian $\mathrm{N}$, poornamdar $\mathrm{Z}$, ghaljeh $\mathrm{M}$. The effect of foot reflexology massage on pain intensity in patients with chronic low back pain visited to physical therapy unit in Baghiathallah hospital in Tehran. طبكمل. 2012 ;2 (3) :211-204

34. Ernst, Edzard. "Is reflexology an effective intervention? A systematic review of randomised controlled trials." Med J Aust 191.5 (2009): 263-6.

35. Quinn, F., G. D. Baxter, and Ciara M. Hughes. "Complementary therapies in the management of low back pain: a survey of reflexologists." Complementary therapies in medicine 16.1 (2008): 9-14.

36. Goats, Geoffrey C. "Massage--the scientific basis of an ancient art: Part 2. Physiological and therapeutic effects." British Journal of Sports Medicine 28.3 (1994): 153-156.

37. Bowsher D. Modulation of noci ceptive input. In:WellsPE, FramptonV, Bowsher D, eds. Pain: Management and Control in Physiotherapy. London, UK: Heinemann Medical, 1988: Chapter 13.

38. Ernst, E; Posadzki, P; Lee, MS (Feb 2011). "Reflexology: an update of a systematic review of randomised clinical trials.". $\begin{array}{lll}\text { Maturitas } & 68 & (2):\end{array}$ 20. 